\title{
Familial cerebral palsy associated with normal intelligence
}

\author{
N.J. Wild* and L. Rosenbloom
}

The Regional Child Development Centre, Alder Hey Children's Hospital, Eaton Road, Liverpool, UK.

\begin{abstract}
Summary: We describe two families affected by a recessively transmitted familial cerebral palsy with onset in infancy. Two sisters in the first family have a severe spastic diplegia. The older sister also has mild mental retardation and hypothyroidism whilst the younger sister is of normal intelligence. Two brothers in the second family have a spastic quadriparesis, fifth finger camptodactyly and normal intelligence.
\end{abstract}

\section{Introduction}

We report two families in which cerebral palsy, first recognized in infancy and associated with normal intelligence, occurred as a recessive trait.

\section{Case reports}

Family $A$ - spastic diplegia

Sibling 1 A 12 year old girl born normally at term after an uneventful pregnancy with a birth weight of $3.2 \mathrm{~kg}$. No resuscitation was required after birth and apart from prolonged jaundice there were no problems in the neonatal period. At 4 months she presented with clinical hypothyroidism, her serum thyroxine level was reported as undetectable, and treatment with thyroxine was commenced. In late infancy her parents noted increasing delay in the motor development of both legs. At 2 years the clinical findings were of a spastic diplegia with mild mental delay. Current examination reveals a severe spastic diplegia. There is slight wasting of the forearm and hand muscles but the upper limb tone and reflexes are normal. Her gait is very abnormal and she has required surgery to maintain limited mobility using a walking aid. The patient is euthyroid and her I.Q., as measured using the WISC verbal scale, is 65 .

Sibling 2 A 10 year old girl born normally at term following an uncomplicated pregnancy with a birth weight of $3.4 \mathrm{~kg}$. No resuscitation was required after birth and the neonatal period was uneventful. From approximately 6 months onwards her parents

\footnotetext{
*Correspondence and present address: N.J. Wild, M.B., B.Ch., D.C.H., M.R.C.P., University Department of Paediatrics and Child Health, D Floor, Clarendon Wing, The General Infirmary at Leeds, Belmont Grove, Leeds LS2 9NS, UK.

Accepted: 7 May 1986
}

observed a similar delay in the motor development of the lower limbs. When examined at 21 months the patient had a spastic diplegia but was not otherwise developmentally delayed. The clinical signs at present are of a severe spastic diplegia, with no abnormal signs in the upper limbs. The patient has had bilateral heel cord and hip adductor release operations and is able to walk with difficulty using arm crutches. There is no evidence of hypothyroidism and a recent intelligence quotient (IQ), as measured using the WISC verbal scale, was 108 .

\section{Family B - spastic quadriplegia}

Sibling 1 A 13 year old boy delivered by forceps at term after a normal pregnancy. The birth weight was $3.2 \mathrm{~kg}$ and no resuscitation was required after delivery. Intermittent vomiting was observed during the neonatal period, and investigation revealed a urinary tract infection which was treated with antibiotics. By 10 months his parents had become increasingly worried by their son's inability to sit and delayed motor development. A spastic quadriparesis was found when the patient was seen aged 16 months. A recent examination revealed spastic quadriparesis, the legs being more severely affected than the arms. The only other abnormal findings were bilateral fifth finger camptodactyly and a fixed flexion deformity of the left wrist which had been present from birth (Figure 1). In spite of surgery to both legs, the patient can only walk with great difficulty using a walking aid. A recent IQ, WISC verbal scale, was 105 .

Sibling 2 A 12 year old boy born normally at term following an uneventful pregnancy with a birth weight of $3.77 \mathrm{~kg}$. No resuscitation was required and there were no problems in the neonatal period. By 7 months the parents had noted similar delay in motor development and at 10 months the clinical findings suggested an emerging spastic quadriparesis. On examination 


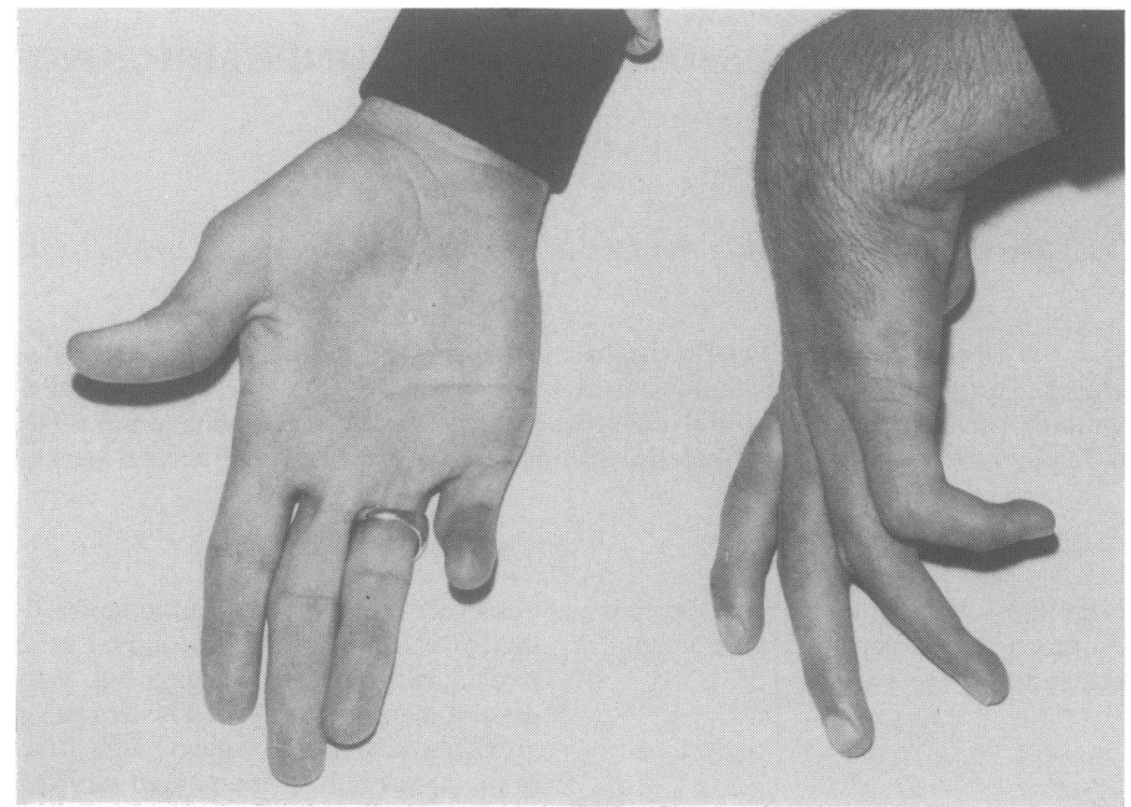

Figure 1 Family B, sibling 1. Bilateral fifth finger camptodactyly with fixed flexion deformity of the left wrist.

the patient now has the signs of a spastic quadriparesis which affects the legs more severely than the arms. There is a mild degree of fifth finger camptodactyly. The patient is only able to walk with difficulty using a walking aid. A recent IQ was measured at 90 , using the WISC verbal scale.

Investigations including skull X-rays and electroencephalograms were normal in all four children. Computerized brain scans were not available at the time. After discussion with the parents it was decided not to perform invasive investigations such as air encephalography.

\section{Family history}

The parents of both these families were well and in neither family was a history of other similarly affected members or consanguinity obtained. There was no evidence of ataxia, atrophy of the hands or pes cavus in either family. Each family had only 2 affected children with no unaffected siblings.

\section{Discussion}

The two families we describe each have two children affected by spastic cerebral palsy. Family $A$ has a disorder characterized by an early onset, with a severe non-progressive spastic diplegia and sparing of in- tellect. The mild mental retardation affecting the first sibling is almost certainly the result of her congenital hypothyroidism which was untreated for the first 4 months of life. Her motor abnormalities are dissimilar from those described previously in hypothyroid patients (MacFaul et al., 1978; Birrell et al., 1983). An autosomal recessive pattern of inheritance is the most likely in this family. In Family B the two brothers are affected by a severe non-progressive spastic quadriparesis with more marked involvement of the legs than the arms. Both affected individuals also have bilateral fifth finger camptodactyly. The likely mode of inheritance in this family is either $\mathrm{X}$-linked recessive or autosomal recessive.

Familial cases of cerebral palsy have been reported by several authors (Hanhart, 1936; Penrose, 1938; Blumel et al., 1957; Adler, 1961; Gudmundsson, 1967; Book \& Sjogren, 1970; Bundey \& Griffiths, 1977). In addition to a spastic diplegia or quadriplegia, affected patients have been mentally retarded and/or had other neurological or physical abnormalities. Familial cases detected in large surveys of cerebral palsy patients have occurred after multiple or premature delivery and it is likely that many of these patients had acquired lesions (Bundey \& Griffith, 1977). This is almost certainly the case in those families in which affected members had dissimilar clinical findings (Asher \& Schonell, 1950; Adler, 1961).

Congenital ataxia and ataxic diplegia have also both been reported in association with moderate or severe 
mental retardation and a recessive pattern of inheritance (Gustavson et al., 1969).

Slowly progressive types of the familial spastic paraplegias, beginning in early childhood, may be difficult to distinguish from diplegic cerebral palsy. These disorders have been described in families showing autosomal dominant, autosomal recessive, and Xlinked patterns of inheritance (McKusick, 1978). There appear to be at least two forms of autosomal dominant disorder (Thurmon \& Walker, 1971); Type I has an onset before 35 years, is slowly progressive and less severe. Type II has a later onset, is more severe and more rapidly progressive (Harding, 1981). Autosomal recessive spastic paraplegia is usually associated with mental retardation (Allport, 1971; Skre, 1974), macular degeneration (Macrae et al., 1974) or cranial nerve involvement (Rothschild et al., 1979). Pure forms of the disorder appear to be uncommon (Aagenaes, 1959; de Coo et al., 1982). Age at onset is usually between 1 and 15 years, although adult onset is described in a small number of patients. X-linked spastic paraplegia has been reported in several kindreds and is usually associated with gradual or rapid progression in affected individuals (Thurmon et al., 1971). However, the disorders affecting our patients

\section{References}

AAGENAES, O. (1959). Hereditary spastic paraplegia: a family with 10 injured. Acta Psychiatrica Neurologica Scandinavica, 34, 489.

ADLER, E. (1961). Familial cerebral palsy. Journal of Chronic Disease, 13, 207.

ALLPORT, R.B. (1971). Mental retardation and spastic paraparesis in four of eight siblings. Lancet, ii, 1089.

ASHER, P. \& SCHONELL, F.E. (1950). A survey of 400 cases of cerebral palsy in childhood. Archives of Disease in Childhood, 25, 360.

BIRRELL, J., FROST, G.J. \& PARKIN, J.M. (1983). The development of children with congenital hypothyroidism. Developmental Medicine and Child Neurology, 25, 512.

BLUMEL, J., EVANS, E.B. \& EGGERS, G.W.N. (1957). Hereditary cerebral palsy: a preliminary report. Journal of Pediatrics, 50, 454.

BOOK, J.A. \& SJOGREN, T. (1970). A pedigree with essential myoclonus and genetic spastic oligophrenia. Clinical Genetics, $1,95$.

BUNDEY, S. \& GRIFFITHS, M.I. (1977). Recurrence risks in families of children with symmetrical spasticity. Developmental Medicine and Child Neurology, 19, 179.

DE COO, I.F.M., GABREELS, F.J.M., RENIER, W.O., COLON, E.J. \& TER HAAR, B.G.A. (1982). Recessively inherited 'pure' spastic paraplegia: case study. Clinical Neurology and Neurosurgery, 84-4, 247.

GUDMUNDSSON, K.R. (1967). Cerebral palsy in Iceland. Acta Neurologica Scandinavica, 43 (Suppl 34), 7.

GUSTAVSON, K.H., HAGBERG, B. \& SANNER, G. (1969). have not progressed over a 10 year period and are therefore unlikely to be one of the familial spastic paraplegias.

The familial cerebral palsies are uncommon conditions with a high recurrence risk whereas cerebral palsy resulting from perinatal asphyxia or other acquired insult is by comparison common and has a low recurrence risk. In those individuals who are found to have cerebral palsy in early childhood, without a clear history of cerebral injury or insult, consideration should be given to the possibility of a genetically transmitted disorder. The two families we describe both have affected individuals without associated mental retardation, showing that normal intelligence does not exclude the possibility of a genetically transmitted cerebral palsy. This is particularly relevant to the counselling of families who have a child with an isolated spastic diplegia and normal intelligence where great care should be taken in eliciting a history of perinatal insult and excluding a family history of the disorder.

We conclude that both spastic quadriplegia and spastic diplegia beginning in infancy and associated with normal intelligence are hitherto undescribed varieties of familial cerebral palsy.
Identical syndromes of cerebral palsy in the same family. Acta Paediatrica Scandinavica, 58, 330.

HANHART, E. (1936). Eine sippe mit einfach-rezessiver diplegia spastica infantilis (littlescher krankheit) aus einem schweizer inzuchtgebiet, Der Erbarzt, 11, 165.

HARDING, A.E. (1981). Hereditary 'pure' spastic paraplegia: a clinical and genetic study of 22 families. Journal of Neurology, Neurosurgery and Psychiatry, 44, 871.

MACFAUL, R., DORNER, S., BRETT, E.M. \& GRANT, D.B. (1978). Neurological abnormalities in patients treated for hypothyroidism from early life. Archives of Disease in Childhood, 53, 611.

MACRAE, W., STIEFFEL, J. \& TODOROV, A.B. (1974). Recessive familial spastic paraplegia with retinal degeneration. Acta Geneticae Medicae Gemellologiae (Roma), 23, 249.

McKUSICK, V.A. (1978). Mendelian Inheritance in Man, 5th edn. p. XLVI. The Johns Hopkins University Press: Baltimore.

PENROSE, L.S. (1938). A clinical and genetic study of 1,280 cases of mental defect. Medical Research Council (London). Special Report Series, No. 229. (Reprinted in 1975 by the Institute for Research into Mental and Multiple Handicap). London.

ROTHSCHILD, H., HAPPEL, L., RAMPP, D. \& HACKETT, E. (1979). Autosomal recessive spastic paralegia: evidence for demyelination. Clinical Genetics, 15, 356.

SKRE, H. (1974). Heredity spastic paraplegia in Western Norway. Clinical Genetics, 6, 165. 
THURMON, T.F. \& WALKER, B.A. (1971). Two distinct types of autosomal dominant spastic paraplegia. The Clinical Delineation of Birth Defects: VI; Nervous System. Birth Defects Original Article Series VII (I): 216. New York. THURMON, T.F., WALKER, B.A., SCOTT, C.I. \& ABBOTT,
M.H. (1971). Two kindreds with a sex-linked recessive form of spastic paraplegia. The Clinical Delineation of Birth Defects: VI; Nervous System. Birth Defects Original Article Series VII (I). 219. New York. 